\title{
Porosity Analysis of Plasma Sprayed Coating by Application of Soft Computing
}

\author{
Ajit Behera, ${ }^{1}$ S. C. Mishra, ${ }^{2}$ Asit Behera, ${ }^{3}$ and J. P. Dhal ${ }^{4}$ \\ ${ }^{1}$ Department of Metallurgical \& Materials Engineering, Indian Institute of Technology, Kharagpur, West Bengal 721302, India \\ ${ }^{2}$ Department of Metallurgical \& Materials Engineering, National Institute of Technology, Rourkela, Odisha 769008, India \\ ${ }^{3}$ Department of Mechanical Engineering, National Institute of Technology, Rourkela, Odisha 769008, India \\ ${ }^{4}$ Department of Chemistry, National Institute of Technology, Rourkela, Odisha 769008, India
}

Correspondence should be addressed to J. P. Dhal; jyoti84.chem@gmail.com

Received 23 January 2013; Accepted 22 March 2013

Academic Editor: Marie-Louise Saboungi

Copyright (C) 2013 Ajit Behera et al. This is an open access article distributed under the Creative Commons Attribution License, which permits unrestricted use, distribution, and reproduction in any medium, provided the original work is properly cited.

\begin{abstract}
The present piece of work describes the industrial wastes and low grade ores (fly ash + quartz + ilmenite, as the coating material), deposited on mild steel substrates. In many cases it is found that porosity is an important factor on the coating surface. Knowledge about the extent of these porosity imperfections is critical since they influence a wide range of spray coated properties and behaviors. To decrease the porosity by optimizing necessary operating parameters, artificial neural network (ANN) technique is used. The aim of this investigation is to find out appropriate input vectors in ANN model. ANN experimental results indicate that the projection network has good generalization capability to optimize the porosity.
\end{abstract}

\section{Introduction}

Plasma surfacing is an excellent technology in highperformance coating applications ranging from aerospace industry to biomedical industry [1-3]. Thermal spraying process implements a wide variety of materials (metal, ceramic, alloy and its composite) and processes (atmospheric plasma spraying, vacuum plasma spraying, etc.) for improving surface properties [4-6]. The conventional plasma-spraying process is commonly referred to as air or atmospheric plasma spraying (APS). To generate plasma, an inert gas typically argon/argon + hydrogen mixture is superheated by a DC arc [7]. Plasma temperatures range from approximately $6000^{\circ} \mathrm{C}$ to $15000^{\circ} \mathrm{C}$ in the power heating region, which are significantly above the melting point of any known material [8]. The powder mixture of fly ash + quartz + ilmenite (size from $40 \mu \mathrm{m}$ to $100 \mu \mathrm{m}$ ) injected into a high-temperature plasma flame which is then rapidly heated and accelerated to a very high velocity by the plasma flame impacts the surface of the substrate material in the form of molten or semimolten state and very quickly cools to form a high-quality coating $[7,9,10]$.
The quality control of plasma spray technique generally considers the monitoring of the molten feedstock particle characteristics deposited at the substrate surface, that is, to increase the coating efficiency [11]. Coating efficiency represents the effectiveness of the deposition process as well as the coatability of the powder under study [12]. The coating efficiency directly or indirectly depends on many other parameters during spraying, in which each one is interrelated with each other. Porosity is a microstructural feature and affects a lot of coating properties such as thermal conductivity, coefficient of thermal expansion, elastic modulus, and dielectric behavior [13]. Various methods are employed for quantitative measurement of porosity and form a necessary part of microstructural characterization of thermal spray coatings. The most used technique is image analysis which is a reliable, straightforward, versatile, and inexpensive technique for the characterization of porosity. ANN study and design of systems are capable of perceiving their environment and taking actions maximizing their chance of success (i.e., to decrease the coating porosity), by considering all of the previously interrelationships. 
TABLE 1: Experimental operating parameters used during plasma spraying of fly ash + quartz + ilmenite.

\begin{tabular}{lc}
\hline Operating parameters & values \\
\hline Plasma arc current (Amp) & $270,300,400$ and 420 \\
Arc voltage (volt) & 40,45 and 50 \\
Torch input power (KW) & $11,15,18$ and 21 \\
Plasma gas (argon) flow rate (IPM) & 28 \\
Secondary gas $\left(\mathrm{N}_{2}\right.$ ) flow rate (IPM) & 3 \\
Carrier gas (Ar) flow rate (IPM) & 12 \\
Powder feed rate (gm/min) & 12,15 and 18 \\
Powder size $(\mu \mathrm{m})$ & $40,60,80$ and 100 \\
Torch-to-base distance $(\mathrm{TBD})(\mathrm{mm})$ & 100 \\
\hline
\end{tabular}

\section{Experimental Procedure}

Fly ash + quartz + illuminate mixture was taken with weight percentage ratio of $60: 20: 20$ and mechanically milled in planetary ball mill for 3 hour for homogenization. This mixture used as feed stock for plasma spraying was first sieved. Four different sizes (i.e., $40 \mu \mathrm{m}, 60 \mu \mathrm{m}, 80 \mu \mathrm{m}$, and $100 \mu \mathrm{m}$ ) are separated out. Mild steel is used as substrate material, having dimensions of 1 inch diameter and $3 \mathrm{~mm}$ thickness. The substrates were grit-blasted at a pressure of $3 \mathrm{~kg} / \mathrm{cm}^{2}$ using alumina grit to make the surface roughness around $5 \mathrm{Ra}$. Then substrates surface was cleaned by acetone and plasma spraying was immediately carried out. In plasma torch input power level was varied from $11 \mathrm{KW}$ to $21 \mathrm{KW}$. This is a typically DC power supplied nontransferred arc mode atmospheric plasma spray process. The injection of the powder was external from the torch nozzle and directed towards the plasma flow. Argon and hydrogen plasma mixture gas is used as carrier gas. The major subsystems of the set-up include the power supply, plasma spraying torch, powder feeder, and carrier gas supply, stand of distance of torch, control console, cooling water, and spray booth. A four-stage closed loop centrifugal pump water cooling system was used for cooling the system and regulated at a pressure of $10 \mathrm{~kg} / \mathrm{cm}^{2}$ supply. Plasma spray operating parameters specifications are given in Table 1. Flow rates of plasma gas (argon) and secondary gas $\left(\mathrm{N}_{2}\right.$ gas) are kept constant. With increasing power level, different parameters such as powder feed rate, powder size, and stand of distance of torch are varied. Experimental value of porosity was measured by image analyzer technique. In image analyzer technique the porosity of coatings was measured by putting polished cross-sections of the sample under a microscope (Neomate made) equipped with a CCD camera (JVC, TK 870E). This system is used to obtain a digitized image of the object. The digitized image is transmitted to VOIS image analysis software. The total area captured by the objective of the microscope or a fraction can be accurately measured by the software. Hence the total area and the area covered by the pores are separately measured.
TABLE 2: Input parameters selected for ANN training.

\begin{tabular}{lc}
\hline Input parameters for training & Values \\
\hline Error tolerance & 0.003 \\
Learning parameter $(\beta)$ & 0.002 \\
Momentum parameter $(\alpha)$ & 0.002 \\
Noise factor (NF) & 0.001 \\
Maximum cycles for simulations & $10,000,000$ \\
Slope parameter $(\mathfrak{E})$ & 0.6 \\
Number of hidden layer neurons & 8 \\
Number of input layer neurons (I) & 5 \\
Number of output layer neurons $(\mathrm{O})$ & 1 \\
\hline
\end{tabular}

\section{Artificial Neural Network}

A neural network is a soft computing model processing of a system, based on interrelationship between different input and output parameters and learning from data set through iteration, without requiring a prior knowledge on the relationships between the process variables [13]. This model is able to approximate various nonlinearities in the data series among other models [14-16] and can give an appropriate optimized data output (here porosity), more quickly [17]. ANN of simple processing elements (neurons) typically organized in layers (input layers, hidden layers, and output layers) is shown in Figure 1. A software package NEURALNET for neural computing is developed, by using back propagation algorithm as the prediction tool for output (coating coating porosity) $[18,19]$.

For developing an ANN there are no fixed rules, but in general framework it can be followed based on previous successful applications in engineering. The aim of an ANN is to normalize an input-output relationship of the form

$$
y^{m}=f\left(x^{n}\right),
$$

where $x^{n}$ is an $n$-dimensional input vector represents variables $x_{1}, \ldots, x_{i}, \ldots, x_{n}$ and $y^{m}$ is an $m$-dimensional output vector that represents the resulting variables $y_{1}, \ldots, y_{i}, \ldots, y_{m}$. In plasma spray modeling, values of $x$ may be current, voltage, stand of distance, powder federate, and powder size.

\section{Results and Discussion}

In NEURALNET Software, based on least error criterion as shown in Table 2, is selected for training of the input-output data by taking 12 sets of parameters. The network training and testing process are conducted for 10,000,000 cycles for which stabilization of the error is obtained. Neuron numbers in the hidden layer are varied and in the optimized structure of the network, this number is 6 for Mild Steel. The three-layer network involved is shown in Figure 1.

\subsection{Predicted Porosity Compared with Experimental Results} Based on Different Feed Rate. Comparative study of ANN prediction value of coating porosity with that of experimental value for mild steel substrate is given in Figure 2. Here the 


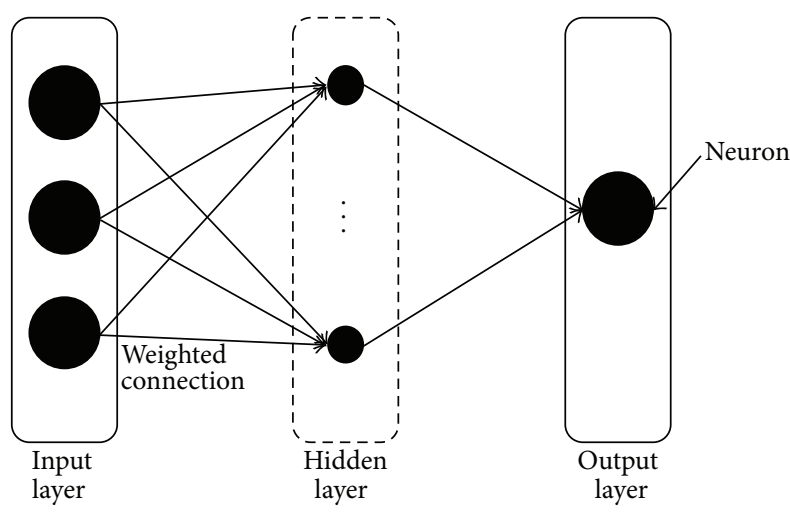

FIGURE 1: Architecture of artificial neural network.

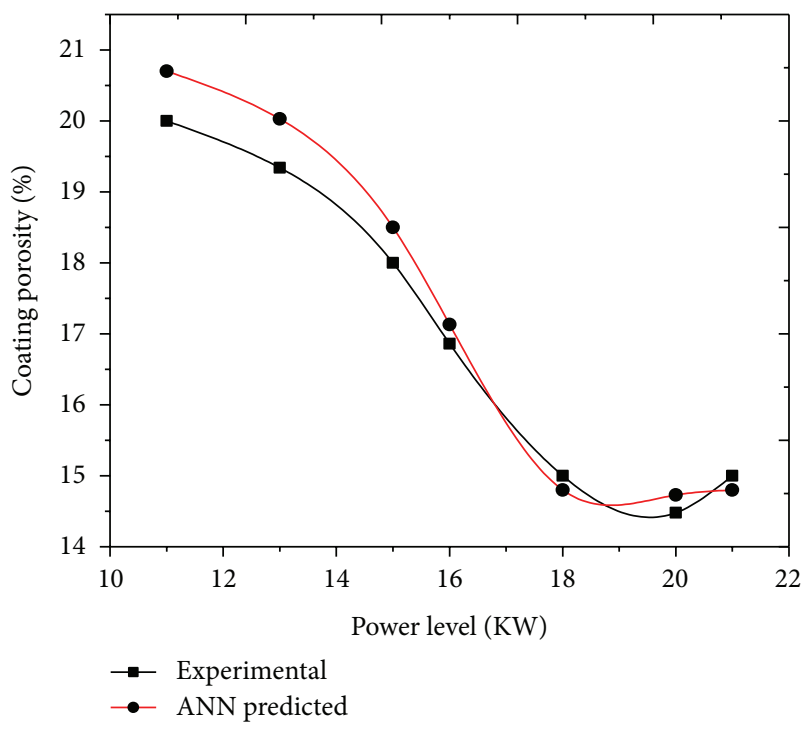

FIgURE 2: Comparison plot between ANN prediction porosity and experimental value at $12 \mathrm{gm} / \mathrm{min}$ feed rate (fly ash + quartz + ilmenite powder mixture is deposited on mild steel substrates).

fly ash + quartz + illmenite composite powder is deposited on mild steel at $12 \mathrm{gm} / \mathrm{min}$ feed rate, $100 \mathrm{~mm}$ torch stand of distance with varying power level. Two sigmoidal plots were found by varying input power level. From this figure, it can be seen that the porosity decreases in between 18 and $20 \mathrm{KW}$ power level. In spraying the exact power level cannot be specified, because thermally sprayed coatings are very complex and incorporate process dependent defects such as splat gaps/interlamellar pores, globular pores, and cracks (for ceramics). It is clear that there is a close agreement of porosity measurement by the neural network and the experimental study, which indicates that the ANN model can be used for predicting the amount coating porosity. At $12 \mathrm{gm} / \mathrm{min}$ feed rate and $100 \mathrm{~mm}$ torch stand of distance; the lowest $(14.48 \%)$ coating porosity is obtained at $20 \mathrm{~kW}$.

From the figures it is found that by increasing power level the porosity value decreases up to a certain point and increases with further increase in power level. This increase

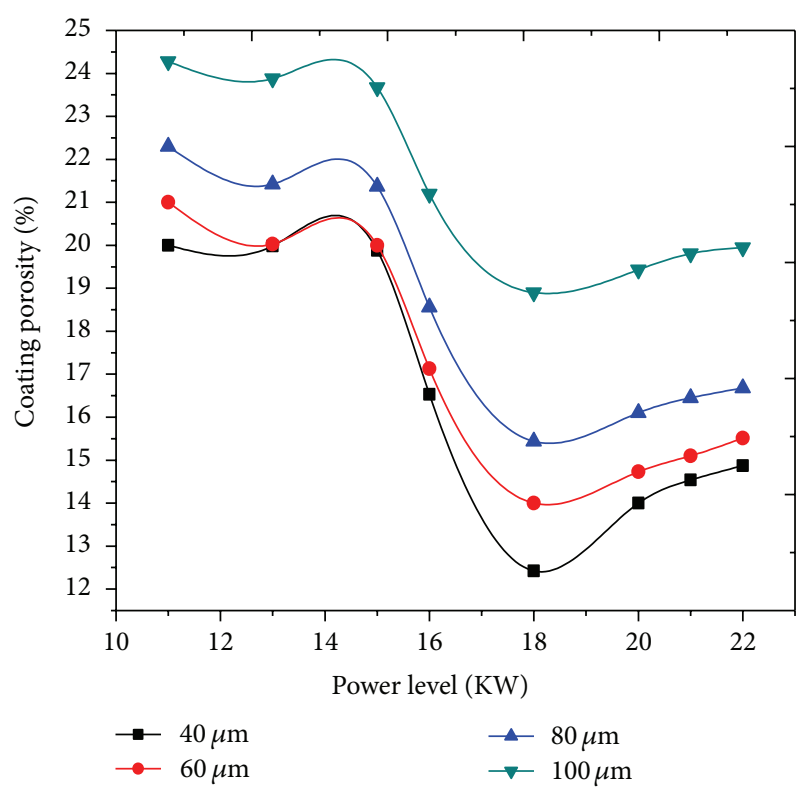

FIGURE 3: ANN results of coating porosity with respect to power level for different powder size at $12 \mathrm{gm} / \mathrm{min}$ feed rate.

is due to formation of vaporized molten powder particle. It is also known that the lesser the coating thickness, the lesser will be the coating porosity [20]. Porosity formation by intersplat position also depends on the mode of heat transfer through the substrate or prior deposited splats. This is also similar to splat quenching by the Duwez gun technique [21].

4.2. Prediction of Porosity Based on Variation of Powder Size. By keeping feed rate $(12 \mathrm{gm} / \mathrm{min})$ constant, all other parameters are changed in ANN plot of Figure 3. It is found that for lower powder particle size, porosity decreases rapidly with increase in power level. At 13 to $15 \mathrm{~kW}$ power level, shown in Figure 3, the porosity value increases. This may be due to inadequate amount of heat flow which results in that molten-semimolten particles gather in a way to form more pores. In Figure 4, here initially, porosity value remains the same with increase in power level and then suddenly decreases up to $19 \mathrm{~kW}$ and then becomes constant. In Figures 3 and 4 , for both feed rates, $402009 \mu \mathrm{m}, 60 \mu \mathrm{m}$, and $80 \mu \mathrm{m}$ powder particle sizes should be better for plasma spraying. In Figure 5, the constant feed rate is $18 \mathrm{gm} / \mathrm{min}$. Here similar tendency is observed as previous plots, that is, Figures 3 and 4. Here it is found that only $40 \mu \mathrm{m}$ and $60 \mu \mathrm{m}$ power particles are better to spray.

Hence, if the feed rate will increase, the powder size should be lower for better plasma spray result.

4.3. Prediction Results of Porosity Based on Variation of Feed Rate. In plots of Figure 6, there are nearly similar results by increase in feed rate from $12 \mathrm{gm} / \mathrm{min}$ to $15 \mathrm{gm} / \mathrm{min}$ at $40 \mu \mathrm{m}$ powder size. Figure 7 indicates that porosity is lower in the case of lower powder particle size, with lower feed rate at nearly $18 \mathrm{~kW}$ power level. But in case of $15 \mathrm{gm} / \mathrm{min}$ feed rate, 


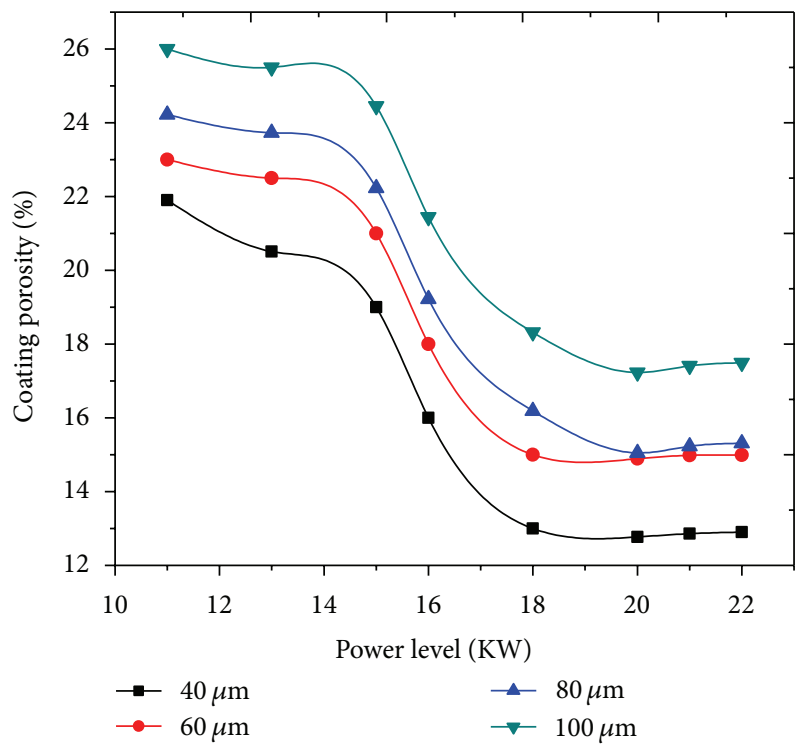

FIGURE 4: ANN results of coating porosity with respect to power level for different powder size at $15 \mathrm{gm} / \mathrm{min}$ feed rate.

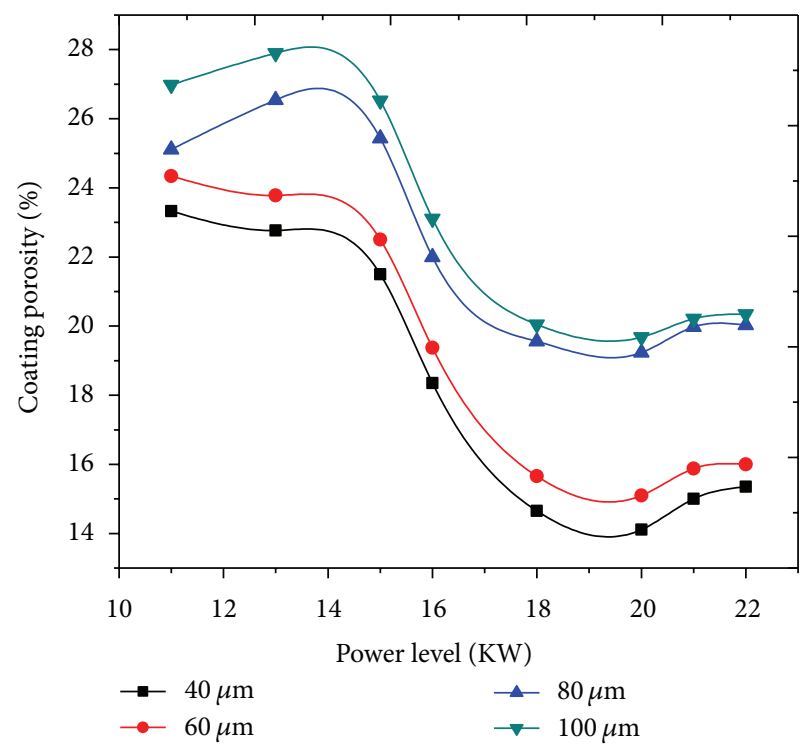

FIGURE 5: ANN results of coating porosity with respect to power level for different powder size at $18 \mathrm{gm} / \mathrm{min}$ feed rate.

porosity remains the same after $18 \mathrm{~kW}$. For $18 \mathrm{gm} / \mathrm{min}$, the plot is as the same as that of $12 \mathrm{gm} / \mathrm{min}$, but porosity value is higher. In Figure 8, ANN result of porosity for $15 \mathrm{gm} / \mathrm{min}$ is lowest at higher power level. In Figure 9, it is observed that the better porosity results at a feed rate of $15 \mathrm{gm} / \mathrm{min}$ for $100 \mu \mathrm{m}$ powder size. In these plots, after $19 \mathrm{~kW}$ power level, the peaks are increases due to the start of vaporization of powder particle.

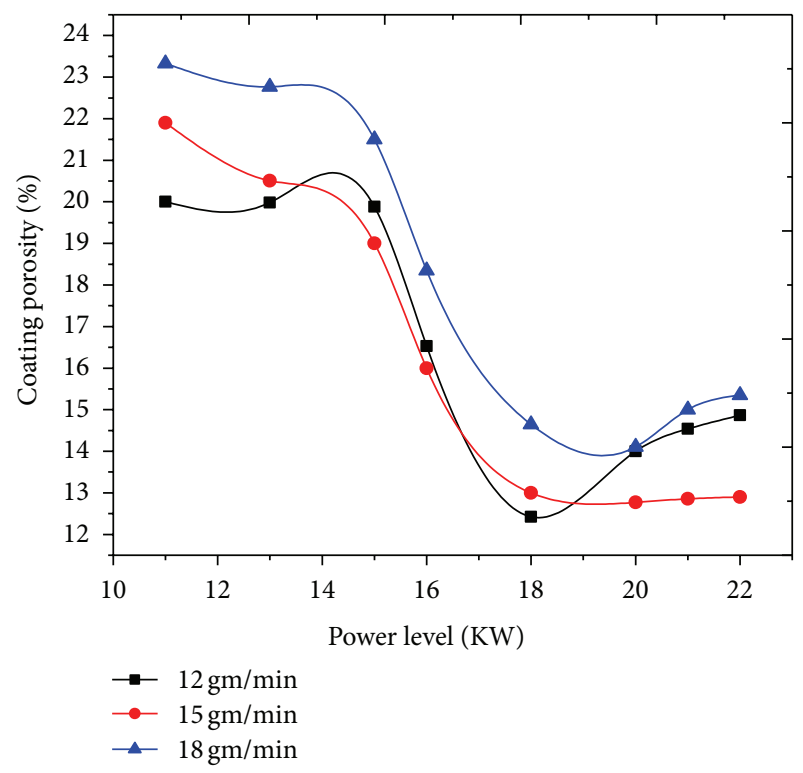

FIGURE 6: ANN results of coating porosity with respect to power level for different feed rate by keeping powder size $40 \mu \mathrm{m}$.

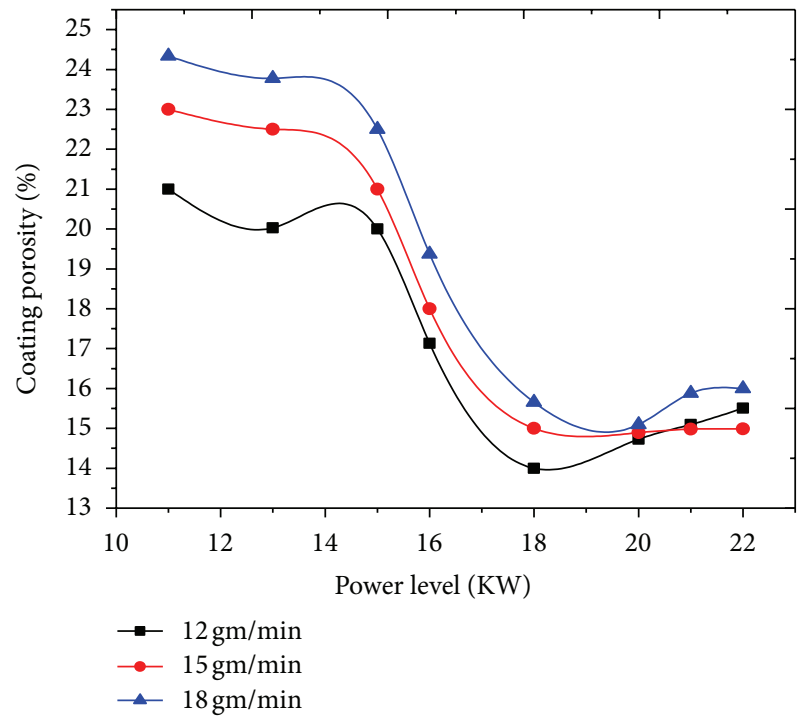

FIGURE 7: ANN results of coating porosity with respect to power level for different feed rate by keeping powder size $60 \mu \mathrm{m}$.

\section{Conclusions}

ANN technique is found to be a convenient and reliable means for optimizing the parameters of thermal spray coatings. The results obtained from ANN have been complemented with those obtained experimentally. From porosity (percentage) value, it is indicated that neural networks can yield fairly accurate results and can be used as a practical tool in plasma spraying manufacturing process. ANN provides the ability to solve the mapping problems much faster than conventional methods. 


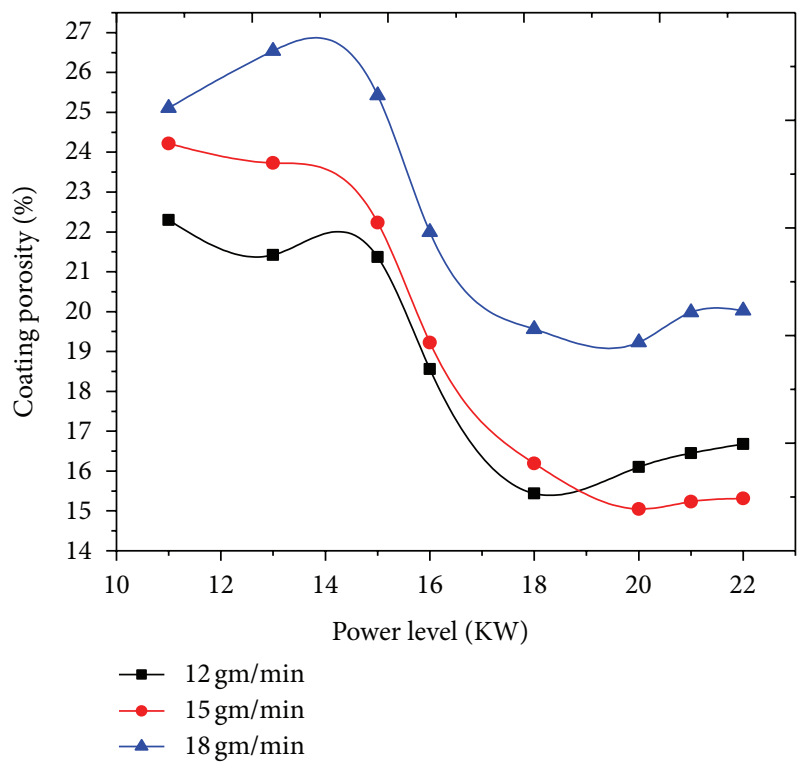

FIGURE 8: ANN results of coating porosity with respect to power level for different feed rate by keeping powder size $80 \mu \mathrm{m}$.

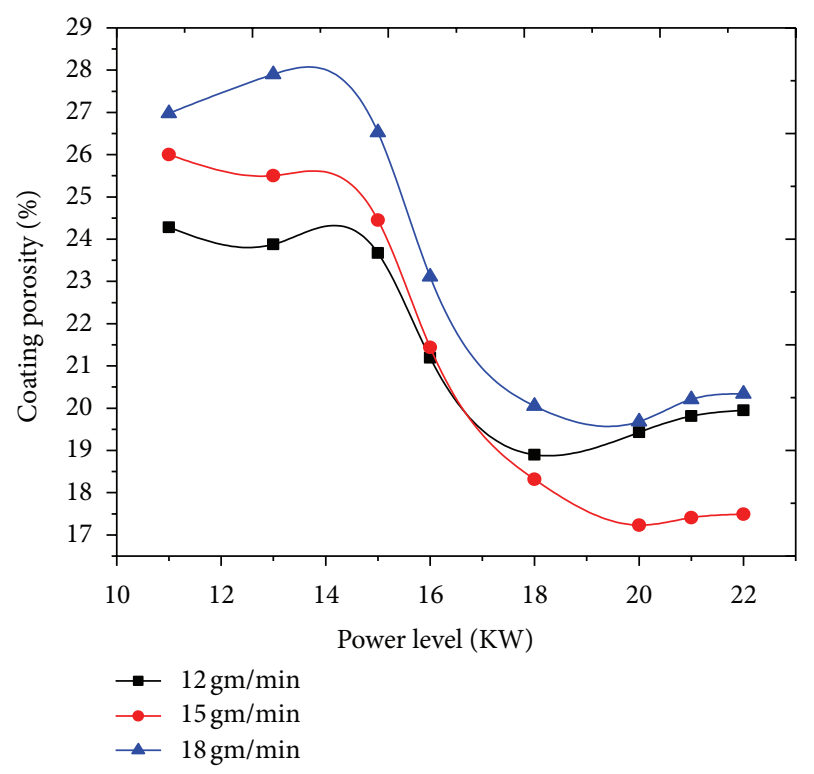

FIGURE 9: ANN results of coating porosity with respect to power level for different feed rate by keeping powder size $100 \mu \mathrm{m}$.

\section{Conflict of Interest}

It is to inform the reader that the "VOIS image analysis software" used in this analysis is being licensed by the authors. Their coauthor Professor S. C. Mishra is having the image analyzer system bearing this software. So there is no conflict of interest of the software.

\section{References}

[1] B. Friedrich-Wilhelm, A. Laarmann, and T. Wenz, Modern Surface Technology, pp. 254-259, John Wiley \& Sons, New York, NY, USA, 2nd edition, 2007.

[2] D. Wixson, "Thermal sprayed-deposits shield structures from corrosion," Indian Welding Journal, vol. 88, no. 7, pp. 67-69, 2009.

[3] H. Shahriar, Design of experiment analysis of high velocity oxyfuel coating of hydroxyapatite [master degree Thesis], School of Mechanical and Manufacturing Engineering, Dublin City University, Dublin, Ireland, 2009.

[4] E. Pfender, in Thermal Spray: Advances in Coatings Technology, D. L. Houck, Ed., vol. 14, pp. 14-17, ASM International, Materials Park, Ohio, USA, 1987.

[5] W. X. Guo, "A method to calculate the evaporation rate of thermal cathode," Journal of Electronics, vol. 6, p. 166, 1984.

[6] J. R. Davis, Handbook of Thermal Spray Technology, Thermal Spray Society Training Committee, ASM International, Materials Park, Ohio, USA, 2004.

[7] M. Zhang, X. Wang, J. Luo, Q. Zhao, and X. Liao, "Influence of plasma spraying on the performance of oxide cathodes," IEEE Transactions on Electron Devices, vol. 58, no. 7, pp. 2143-2148, 2011.

[8] R. B. Heimann, Plasma Spray Coating: Principles and Applications, WILEY-VCH, New York, NY, USA, 2008.

[9] P. Fauchais, "Understanding plasma spraying," Journal of Physics D, vol. 37, pp. 86-108, 2004.

[10] C. Moreau, P. Gougeon, M. Lamontagne et al., Thermal Spray Industrial Applications, ASM International, Materials Park, Ohio, USA, 1994.

[11] S. C. Mishra and A. Satapathy, "Neural network analysis for deposition of nickel-aluminide coatings on steel by plasma spraying," in Proceedings of the 21st National Symposium of Plasma Science Society of India, MNIT, December 2006.

[12] S. S. Sablani, O. D. Baik, and M. Marcotte, "Neural networks for predicting thermal conductivity of bakery products," Journal of Food Engineering, vol. 52, no. 3, pp. 299-304, 2002.

[13] S. Deshpande, A. Kulkarni, S. Sampath, and H. Herman, "Application of image analysis for characterization of porosity in thermal spray coatings and correlation with small angle neutron scattering," Surface and Coatings Technology, vol. 187, no. 1, pp. 6-16, 2004.

[14] M. Friis and C. Persson, "Process window for plasma spray processes," in Thermal Spray 2001: New Surfaces for a New Millenium, C. C. Berndt, K. A. Kohr, and E. F. Lugscheider, Eds., pp. 1313-1319, ASM International, Materials Park, Ohio, USA, 2001.

[15] S. Kundas, "Computer simulation of plasma spraying processes," in Thermal Spray 2001: New Surfaces for a New Millenium, pp. 925-932, ASM International, Materials Park, Ohio, USA, 2001.

[16] P. Fauchais, G. Montavon, M. Vardelle, and J. Cedelle, "Developments in direct current plasma spraying," Surface \& Coatings Technology, vol. 201, no. 5, pp. 1908-1921, 2006.

[17] H. Cetinel, M. Toparli, and L. Özsoyeller, "Finite element based prediction of the microstructural evolution of steels subjected to the Tempcore process," Mechanics of Materials, vol. 32, no. 6, pp. 339-347, 2000.

[18] V. Rao and H. Rao, C++ Neural Networks and Fuzzy Systems, BPB, New Delhi, India, 2000. 
[19] A. Verikas and M. Bacauskiene, "Using artificial neural networks for process and system modelling," Chemometrics and Intelligent Laboratory Systems, vol. 67, no. 2, pp. 187-191, 2003.

[20] A. Behera and S .C. Mishra, "Dependence of adhesion strength of plasma spray on coating surface properties," Journal of Materials \& Metallurgical Engineering, vol. 2, no. 1, pp. 23-30, 2012.

[21] P. Duwez, "Structure and properties of alloys rapidly quenched from the liquid state," ASM Transactions, vol. 60, pp. 607-633, 1967. 

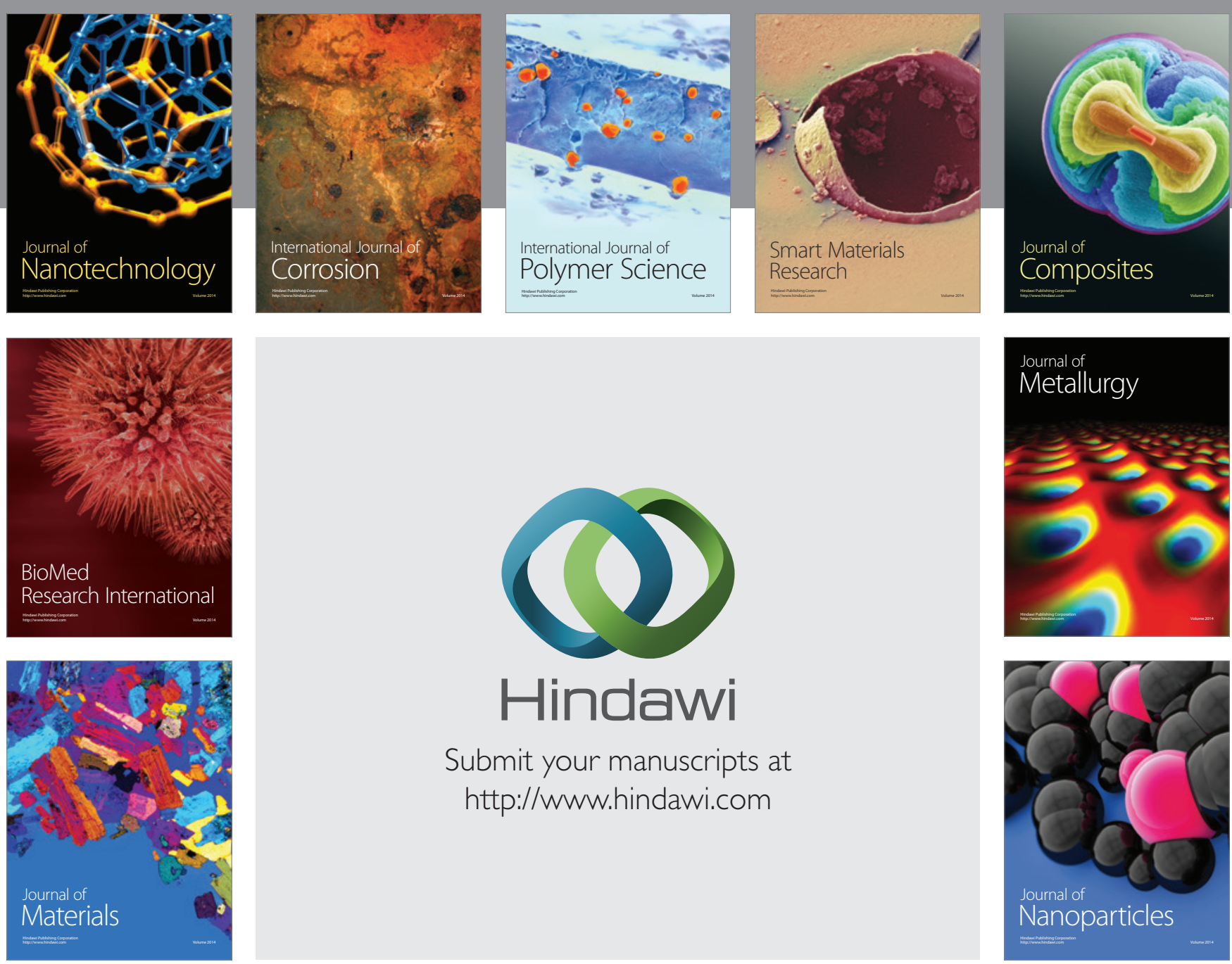

Submit your manuscripts at http://www.hindawi.com
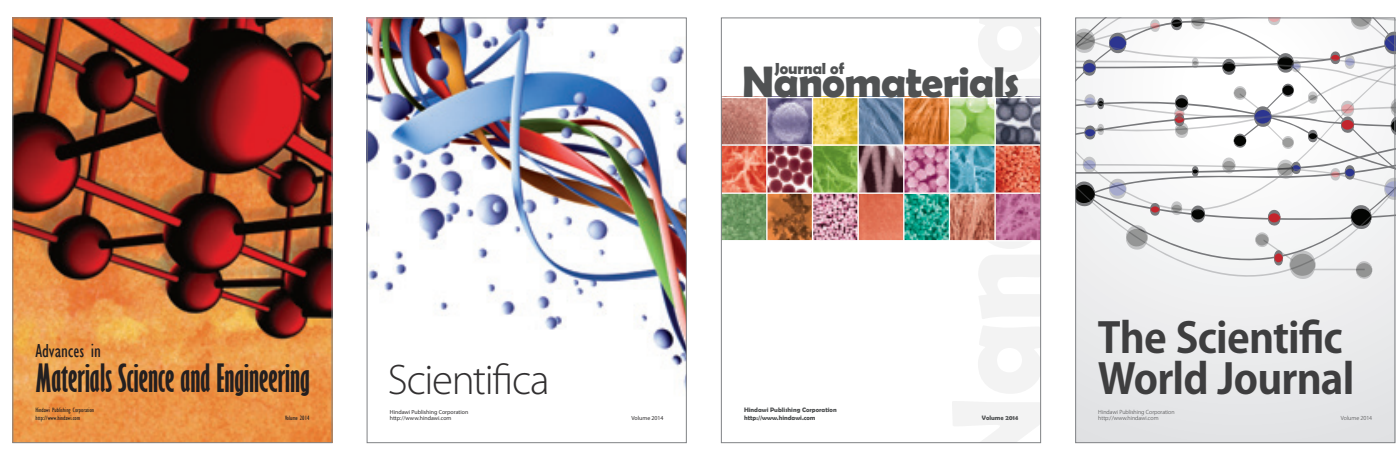

\section{The Scientific World Journal}
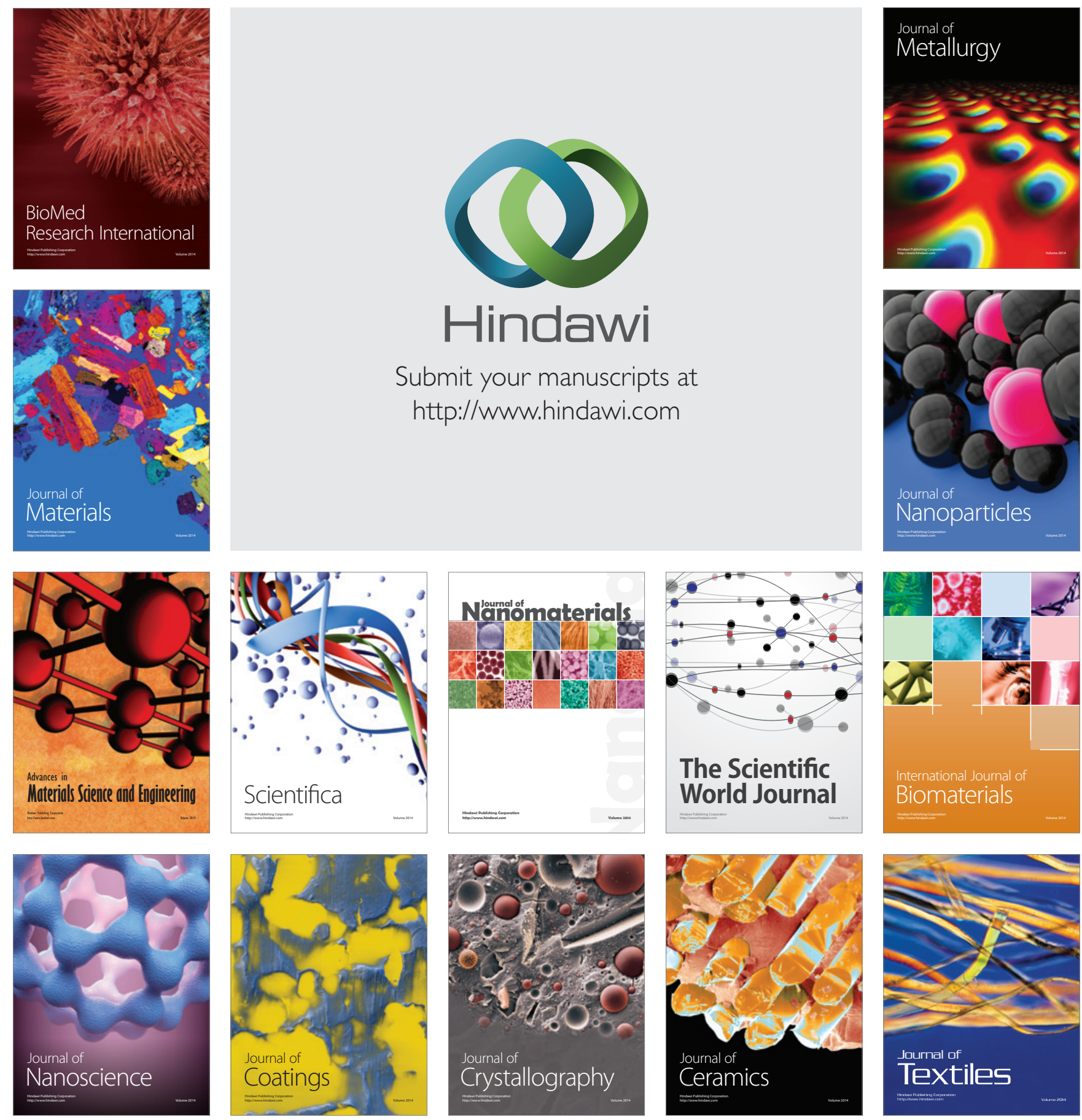